\title{
Identificação biológica e molecular de vírus detectados em espécies de cucurbitáceas provenientes do Estado do Tocantins
}

\section{Molecular biological identification of detected viruses in cucurbit species from the State of Tocantins}

\author{
Nara Edreira Alencar'1, Antônia dos Reis Figueira', João Eduardo Melo de Almeida ${ }^{\mathbf{1}}$, \\ Maurício Antônio Lucas ${ }^{1}$, Luniara Bastos dos Santos ${ }^{2}$ e Ildon Rodrigues do Nascimento ${ }^{2 *}$ \\ ${ }^{1}$ Departamento de Fitopatologia; Universidade Federal de Lavras;37200-000; Lavras - MG - Brasil. \\ 2Departamento de Agronomia; Universidade Federal do Tocantins; 77402-970; Gurupi - TO - Brasil.
}

\begin{abstract}
Cucurbit crops may be affected by several virus diseases, which might cause up to $100 \%$ of yield losses. Due to its environmental conditions, favorable to the emergence of viruses, the state of Tocantins has shown a high incidence of virus diseases in the field. The main objective of this study was to identify and characterize, serological. Biological and molecularly, 25 virus isolates from pumpkin and watermelon collected in some regions of this state showing characteristic symptoms of viruses. Fourteen (56\%) of the 25 isolates studied, were identified as Squash mosaic virus (SqMV). Seven of them were detected in Caserta squash and another seven in watermelon. The remaining isolates were identified as Zucchini yellow mosaic virus (ZYMV). SqMV showed higher incidence when compared to the other Brazilian States, where it normally either have not been detected or detected in very low incidence. It shows the importance of SqMV for Tocantins region.
\end{abstract}

Key-words: Zucchini yellow mosaic virus, DAS-ELISA, RT-PCR

\section{INTRODUÇÃO}

Entre as famílias botânicas utilizadas para a produção de alimentos, as cucurbitáceas destacamse pela importância econômica e social, desde a geração de empregos diretos e indiretos, ligados à necessidade de grande número de mão de obra do cultivo, até a comercialização. $O$ cultivo de cucurbitáceas é praticado tanto em pequenas propriedades, em regime de agricultura familiar, quanto em grandes propriedades. A família Cucurbitaceae é constituída por aproximadamente 118 gêneros e cerca de 825 espécies. As espécies com maior expressão econômica no Brasil são as pertencentes aos gêneros Citrullus (melancia), Cucumis (pepino, maxixe e melão), Cucurbita (moranga, abóbora e abobrinha), Lagenaria (cabaça-caxi) e Sechium (chuchu) (Pinto, 2003). As cucurbitáceas nodem ser afetadas nor várias doenças, dentre elas as viróticas, que podem levar a perdas de até $100 \%$ da sua produção. As plantas infectadas por vírus podem apresentar mosaico, redução do limbo foliar e deformação nas folhas e frutos, podendo a sintomatologia variar com o vírus, com o hospedeiro infectado e com a ocorrência de infecções mistas (Ramos et al., 2003). Sabe-se que a ocorrência de viroses depende de inúmeros fatores, como a época do ano, o local de plantio, a presença e a preferência de vetores, dentre outros (Guner e Wehner, 2008). Dessa forma, o monitoramento da ocorrência de vírus em cucurbitáceas torna-se necessário, não só nos campos de produção, mas como forma de se evitar que as mesmas constituam hospedeiras alternativas de viroses, que também afetam economicamente culturas vizinhas. Devido às suas condições climáticas, favoráveis às viroses, o

Author for correspondence: ildon@uft.edu.br 
estado do Tocantins tem apresentado uma grande incidência dessas doenças no campo. A identificação de espécies de vírus é o passo inicial para desenvolver programas de melhoramento visando à resistência a doenças em cucurbitáceas em uma região. Assim sendo, este trabalho teve como finalidade identificar sorológica, biológica e molecularmente isolados de abóbora e melancia coletados nesse estado. Essa identificação e caracterização de viroses que ocorrem em cucurbitáceas, no Tocantins, representam um importante subsídio para os programas de melhoramento desenvolvidos na Universidade Federal do Tocantins (UFT) e para o controle de viroses de cucurbitáceas nos campos de produção.

\section{MATERIAL E MÉTODOS}

\section{Diagnose e estudo dos vírus}

O trabalho foi conduzido nas dependências do Departamento de Fitopatologia (DFP) da Universidade Federal de Lavras (UFLA). Vinte e cinco amostras foliares de cucurbitáceas, sendo catorze de abóbora 'Caserta', uma de 'Kabutiá' e dez de melancia, foram coletadas em áreas produtoras do Rio Formoso (Formoso do Araguaia), Lagoa da Confusão, Porto Nacional e Gurupí, no estado do Tocantins (Tabela 1). Os isolados obtidos foram inoculados em plantas de Cucurbita pepo cv. Caserta, as quais foram mantidas em casa de vegetação. Para cada vírus inoculado foram utilizadas duas repetições de cada planta a ser testada. A obtenção dessas plantas se deu por meio de semeaduras em bandejas de plástico, empregando-se o substrato apropriado (Plantmax $\left.{ }^{\circledR}\right)$, com posterior transplante para vasos, com capacidade de $2 \mathrm{~kg}$, contendo terra, areia e esterco, na proporção 2:2:1. A inoculação mecânica foi feita quando a planta apresentou o primeiro par de folhas definitivas, no estágio de dois terços de sua expansão definitiva. A inoculação mecânica foi feita com o extrato de folhas jovens, das plantas infectadas, obtido por maceração em almofariz de porcelana na presença de tampão fosfato $0,01 \mathrm{M}, \mathrm{pH} \mathrm{7,0}$ acrescido de sulfito de sódio na mesma molaridade, na proporção de 1:10 (peso/volume). O extrato foi friccionado nas folhas das plantas-teste receptoras, previamente polvilhadas com o abrasivo carbureto de silício (Carborundum) e, em seguida, as plantas foram lavadas com água corrente. Plantas sadias, inoculadas somente com a solução extratora, serviram como controle. As plantas inoculadas foram mantidas em casa de vegetação até o final da avaliação dos sintomas, que foi feita de acordo com a escala de notas desenvolvida por Moreira (2009), sendo: 0 - sem sintomas; 1 - mosaico fraco sem deformações foliares e bom desenvolvimento; 2 - mosaico moderado e pouca deformação foliar; 3 - mosaico e deformação foliar moderada; 4 mosaico intenso e deformação foliar; 5 - mosaico e deformação foliar intensos e desenvolvimento reduzido. Foram realizados dois ensaios, sendo um na época mais quente (março/2010), quando a temperatura variou entre $20^{\circ} \mathrm{C}$ e $35^{\circ} \mathrm{C}$ e o outro na época mais fria (julho/2010), com a temperatura variando entre $5^{\circ} \mathrm{C} \mathrm{e} 25^{\circ} \mathrm{C}$. Estas duas épocas foram escolhidas para se verificar o comportamento do vírus quando as plantas inoculadas foram colocadas em diferentes temperaturas.

Tabela 1. Identificação dos isolados coletados em diferentes locais do estado do Tocantins, infectando plantas de abóbora e melancia.

\begin{tabular}{ccc}
\hline Isolado & Local de coleta & Espécie infectada \\
\hline PTY1 & Chácara Gurupi & Abóbora Caserta \\
PTY2 & Chácara Gurupi & Abóbora Caserta \\
PTY3 & Chácara Gurupi & Abóbora Caserta \\
PTY4 & Chácara Gurupi & Abóbora Caserta \\
PTY5 & Chácara Gurupi & Abóbora Caserta \\
PTY6 & Campo UFT Gurupi & Abóbora Caserta \\
PTY7 & Campo UFT Gurupi & Kabotiá \\
PTY9 & Campo UFT Gurupi & Abóbora \\
& Caserta \\
PTY10 & Campo UFT Gurupi & Melancia \\
PTY11 & Campo UFT Gurupi & Melancia \\
PTY12 & Chácara Gurupi & Abóbora Caserta \\
\hline PTY13 & Chácara Gurupi & Abóbora Caserta \\
PTY14 & Chácara Gurupi & Abóbora Caserta \\
PTY15 & Chácara Gurupi & Abóbora Caserta \\
PTY16 & Chácara Gurupi & Abóbora Caserta \\
PTY17 & Chácara Gurupi & Abóbora Caserta \\
PTY18 & Chácara Gurupi & Abóbora Caserta \\
& Formoso do & \\
FA1 & Araguaia & Melancia \\
GR1 & Gurupi & Melancia \\
GR2 & Gurupi & Melancia \\
LC1 & Lagoa da Confusão & Melancia \\
LC2 & Lagoa da Confusão & Melancia \\
LC3 & Lagoa da Confusão & Melancia \\
PN1 & Porto Nacional & Melancia \\
PN2 & Porto Nacional & Melancia \\
\hline & &
\end{tabular}




\section{Identificação sorológica}

Após o aparecimento dos sintomas nas plantas inoculadas, as folhas foram coletadas e submetidas ao teste de diagnose por DAS-ELISA (Clark e Adams, 1977) com antissoro policlonal específicos para o Squash mosaic virus (SqMV) e o Cucumber mosaic virus (CMV), produzidos pela Bioreba,. O procedimento foi o recomendado pelo fabricante.

\section{Identificação molecular}

Nos testes de diagnose, por meio de RT-PCR, foram empregados os seguintes primers, desenhados com base nos genomas disponíveis no GenBank: SqMV: Foward: 5'TTTGACGGCATGGTC 3' e Reverse: 5' GGAAAGAAGCCACAAC 3'), CMV: Foward: 5'- TCATGGATGCTTCTCC -3' e Reverse: 5'GCTGGATGGACAACC -3' ), Papaia ringspot virus $\mathrm{P}$ (PRSV-P): Foward: 5'GCTGTGGATGCTGGTTTGA -3' e Reverse: 5'CTAAAAGCACGGAGG -3'); Watermelon mosaic virus (WMV: Foward: 5'CAGTGTCTCTGCAATCAGGA -3' e Reverse: 5'- CCCTTGCAGTGTGCCTCTCAG -3'. Para os vírus PRSV-W e para o Zucchini yellow mosaic virus (ZYMV), foram empregados os primers descritos por Stipp (2009), como segue: PRSV W: Foward: 5'- GATTTGAATGAGCAACAGATGG -3' C Reverse: 5' CTCCGCTGCATCTGAGAAGT -3'); ZYMV: Foward: GATTTGAATGAGCAACAGATGG-3' e Reverse:5'-CTCCGCTGCATCTGAGAAGT-3'; A extração do RNA das folhas das plantas infectadas foi feito pelo método do Trizol. A transcrição reversa foi realizada empregando-se $0,5 \mu \mathrm{L}$ do primer reverse, $1,0 \mu \mathrm{L}$ do RNA extraído e 4,0 $\mu \mathrm{L}$ de água ultrapura tratada com DEPC em um microtubo que foi inicialmente incubado por 5 minutos, a $75^{\circ} \mathrm{C}$ e, após este tempo, foi imediatamente transferido para o gelo. Em seguida, acrescentaram-se 2,0 $\mu \mathrm{L}$ de tampão da transcriptase reversa (RT M-MLV - USB), $0,5 \mu \mathrm{L}$ de dNTP a $10 \mathrm{mM}, 0,2 \mu \mathrm{L}$ da enzima RT (USB) e $1,8 \mu \mathrm{L}$ de água ultrapura tratada com DEPC. Os tubos foram incubados a $42^{\circ} \mathrm{C}$, por 30 minutos, depois a $95^{\circ} \mathrm{C}$, por 5 minutos e transferidos para o gelo. Para a reação de PCR, utilizou-se o tampão, $\mathrm{MgCl}_{2}(25 \mathrm{mM})$, dNTP $10 \mathrm{mM}$, primer senso (primer forward) e antissenso (primer reverse), enzima Go Taq Flexi DNA polimerase (Promega), cDNA, completando-se o volume de $50 \mu \mathrm{L}$ com água ultrapura tratada com DEPC. A amplificação consistiu de desnaturação inicial de $95^{\circ} \mathrm{C}$, por 2 minutos, seguida de 35 ciclos de amplificação: $72^{\circ} \mathrm{C}, 30$ segundos; $49^{\circ} \mathrm{C}$ para o SqMV, $50,7^{\circ} \mathrm{C}$ para ZYMV $, 45,5^{\circ} \mathrm{C}$ para o PRSV-P, $55^{\circ} \mathrm{C}$ para o WMV e CMV e $50^{\circ} \mathrm{C}$ para PRSV-W, por um minuto; $72^{\circ} \mathrm{C}$, por 2 minutos e uma extensão final de $72^{\circ} \mathrm{C}$. O produto da RT-PCR foi analisado por eletroforese em gel de agarose $0,7 \%$, corado com GelRed (Biotium).

\section{RESULTADOS E DISCUSSÃO}

Dos 25 isolados analisados, nenhum reagiu com o antissoro para o vírus do mosaico do pepino (CMV). Por outro lado, catorze isolados, ou seja, $56 \%$, foram identificados como Squash mosaic vírus, tendo sete deles sido provenientes de abóbora Caserta e 7 de melancia. Isso mostrou, portanto, a prevalência do SqMV nas regiões onde as amostras foram coletadas. Além de ser o primeiro relato da presença desse vírus no estado do Tocantins, esses resultados foram surpreendentes, pois o SqMV não é considerado de grande importância no Brasil (Oliveira et al., 2000; Moura et al., 2001; Halfeld-Vieira et al., 2004). Além disso, esse vírus, geralmente, tem sido encontrado em plantas de abóbora, ao passo que metade dos isolados positivos para SqMV, detectados, estavam infectando naturalmente melancia no campo. Silveira et al. (2009) realizaram ampla coleta de amostras na região do submédio São Francisco e observaram que o vírus que ocorreu em maior incidência foi o PRSV-W, seguido pelo PRSV-P e ZYMV, nessa ordem, não tendo sido detectada nenhuma planta infectada com o SqMV. Eles sugeriram que os programas de melhoramento genético na região nordeste deveriam considerar fontes de resistência para os três vírus prevalentes, o que não poderia ser considerado no estado de Tocantins, onde a incidência de SqMV foi bastante alta nas amostras analisadas. Um levantamento mais amplo, com maior número de amostras, seria indicado para um resultado mais representativo.

Os isolados denominados PTY1, PTY2, PTY4, PTY5, PTY10, PTY12, PTY14, PTY15, FA1, GR2, LC2, LC3, PN1 e PN2, positivos para o SqMV, no DAS-ELISA e no RT-PCR, tendo sido obtida banda de 818 pb com o par de primers empregado (Figura 1). Essa região amplificada compreende uma parte da região $3^{\prime}$ da proteína maior (L proteína) e toda a proteína menor (SM) do capsídeo desse vírus. Os demais isolados 
(PTY3, PTY6, PTY7, PTY9, PTY11, PTY13, PTY16, PTY17, PTY18, GR1 e LC1), quando testados por RT-PCR, permitiram a amplificação de uma banda de 200 pb (Figura 2), quando se empregou o par de primers específicos para o ZYMV, sendo, portanto, positivos para esse vírus. Todas as 25 amostras, embora tenham sido testadas com os primers para CMV, PRSV P e W e WMV, mostraram resultado negativo, não havendo amplificação de bandas para nenhum delas. Sabe-se que o índice de infecções mistas é elevado pelo fato de várias espécies de vírus serem transmitidas de forma não persistente por várias espécies de afídeos (Silveira et al., 2009). Entretanto, nesse trabalho nenhuma das amostras analisadas apresentou infecções mistas.

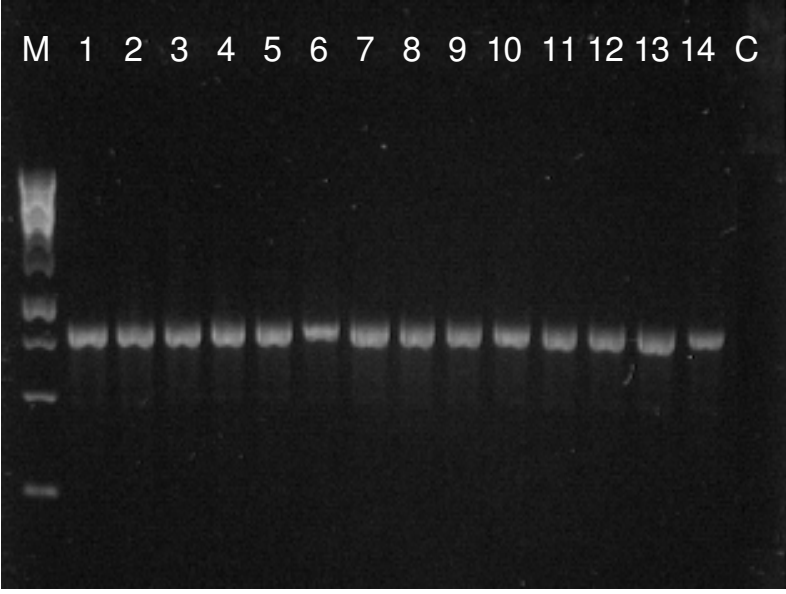

Figura 1- Análise eletroforética das bandas amplificadas com os primers desenhados para Squash mosaic virus. M: $1 \mathrm{~Kb}$ DNA ladder; 1 a 14: isolados: PTY-1, PTY-2, PTY-4, PTY-5, PTY-10, PTY-12, PTY-14, PTY-15, FA, GR2, LC2, LC3, PN1 e PN2. C: controle negativo.

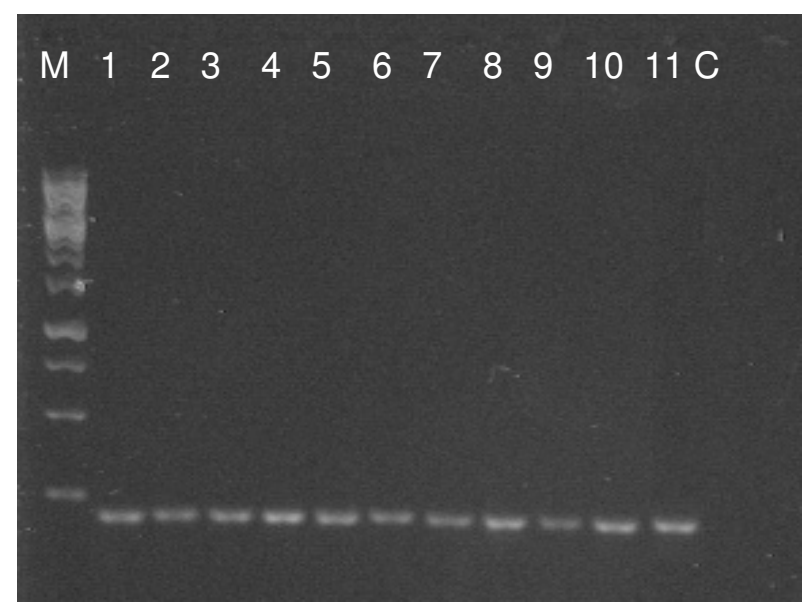

Figura 2 - Análise eletroforética das bandas amplificadas com os primers desenhados para Zucchini yellow mosaic virus. M: $1 \mathrm{~Kb}$ DNA ladder; 1 a 11: isolados PTY-3, PTY-6, PTY-7, PTY-9, PTY-11, PTY13, PTY-16, PTY-17, PTY-18, GR1 e LC1. C: controle negativo.

Os sintomas apresentados pelas plantas de Cucurbita pepo cv. Caserta inoculadas mecanicamente na primeira época de avaliação, no verão, pelos diferentes isolados, foram mais severos para a maioria dos isolados. Com exceção dos sintomas induzidos pelos isolados de SqMV, denominados PTY4 e PTY14, que foram avaliados com a nota 4, todos os isolados, tanto de SqMV como de ZYMV induziram sintomas que receberam nota 5. Por outro lado, a grande maioria das plantas inoculadas no inverno, de ambos os vírus, apresentou sintomas avaliados com a nota 4 , tendo apenas cinco deles, o PTY9 (ZYMV) e PN1, FA1, LC3, PN2 (SqMV), induzido sintomas severos (nota 5) nas plantas infectadas. Moura et al. (2005) também verificaram que a incidência dos sintomas em acessos de abóbora para ZYMV no verão foi mais intensa do que no inverno. A maioria dos sintomas apresentados pelas plantas inoculadas com os isolados de SqMV se caracterizou por mosaico, deformação foliar, banda ao longo das nervuras e subdesenvolvimento da planta (Figura 3).

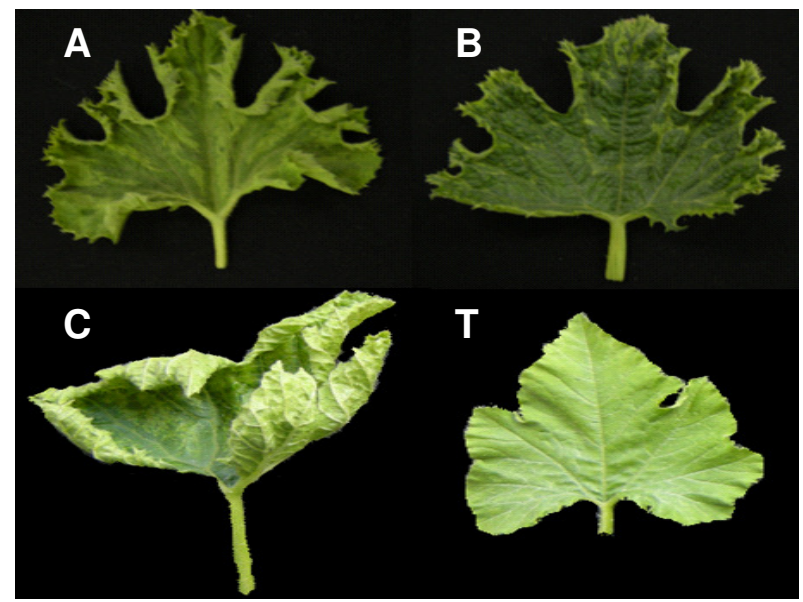

Figura 3 - Padrão dos sintomas dos isolados em Cucurbita pepo cv. Caserta. A, B e C: Mosaico, redução e deformação foliar, mosaico, bolhamento e "dark green vein-banding"; T: testemunha.

O isolado PN1 (SqMV), apresentou-se bem mais agressivo no verão, levando a planta à morte aos catorze dias após a inoculação.

O Squash mosaic virus tem sido considerado de menor importância no território brasileiro, de modo que, em algumas regiões, como no nordeste do Brasil, considera-se que os 
programas de melhoramento devem buscar resistência apenas para o PRSV, estirpes W e P, e para o ZYMV. Entretanto, os resultados aqui obtidos mostraram que essa não é a mesma realidade que ocorre no estado do Tocantins, onde a maioria das amostras estava infectada com esse vírus. Isso demonstra que ou o SqMV pode ter encontrado as condições ideais na região do Tocantins para se disseminar e infectar as hospedeiras locais, ou tem sido introduzido por meio de sementes contaminadas, uma vez que esse vírus é facilmente transmitido pelas sementes.

\section{RESUMO}

As cucurbitáceas podem ser afetadas por várias doenças, dentre elas as viróticas, as quais podem provocar perdas de até $100 \%$ da produção. Devido às condições climáticas, serem favoráveis a ocorrência de viroses, o estado do Tocantins tem apresentado grande incidência dessas doenças no campo. Este trabalho foi realizado com a finalidade de identificar sorológica e molecularmente 25 isolados de abóbora e melancia coletados em diversos municípios do estado que apresentavam sintomas característicos de viroses. Catorze dos 25 isolados estudados, ou seja, $56 \%$, foram identificados como Squash mosaic virus (SqMV), tendo sete deles sido provenientes de abóbora 'Caserta' e sete de melancia. Os demais isolados foram identificados como Zucchini yellow mosaic virus (ZYMV). Ao contrário do que ocorre em outras regiões brasileiras, o SqMV foi o vírus com maior incidência nas amostras coletadas em Tocantins, indicando a sua importância para a região.

Palavras-chave: Vírus do mosaico amarelo, DASELISA, RT-PCR

\section{REFERÊNCIAS}

Clark, M. F.; Adams, A, N. (1977), Characteristics of the microplate method of enzyme-linked immunosorbent assay for the detection of plant viruses. Journal of General Virology, 34, 475483.

Guner, N. e Wehner, T. C. (2008), Overview of Potyvirus resistance in watermelon. In: Cucurbitaceae - Proceedings of the IXth EUCARPIA meeting on genetics and breeding of Cucurbitaceae, 445-452.

Halfeld-Vieira, B. A.; Ramos, N. F.; Rabelo Filho, F. A. C.; Gonçalves, M. F. B.; Nechet, K. L.; Pereira, P. R. V. S.; Lima, J. A. A. (2004), Identificação sorológica de espécies de potyvirus em melancia, no estado de Roraima. Fitopatologia Brasileira, 29, 687-689.

Moreira, A. G. Caracterização de novos isolados fracos do vírus do mosaico do mamoeiro ocorrendo naturalmente no estado do Espírito Santo; Avaliação da infecção natural de cucurbitáceas com esses vírus; Caracterização de um isolado do mosaico da alfafa infectando mamoeiro (Carica papaya) em campo. Tese (Doutorado em Fitopatologia) - Escola Superior de Agricultura "Luiz de Queiroz", Universidade de São Paulo, Piracicaba, 2009.

Moura, M. C. C. L.; Lima J. A. A.; Oliveira V. B.; Gonçalves M. F. B. (2001), Identificação sorológica de espécies de vírus que infetam cucurbitáceas em áreas produtoras do Maranhão. Fitopatologia Brasileira, 26, 90-92.

MOURA, M.C.C.L.; ZERBINI, F.M.; SILVA, D.J.H.; QUEIROS, M.A. Reação de acessos de Cucurbita sp. ao Zucchini yellow mosaic vírus (ZYMV). Horticultura Brasileira, v.23, p. 206$210,2005$.

Oliveira, V. B.; Lima, J. A. A.; Vale, C. C.; Paiva, W. O. (2000), Caracterização biológica e sorológica de isolados de potyvirus obtidos de cucurbitáceas no Nordeste brasileiro. Fiopatologia Brasileira, 25, 628-636. 2000.

Pinto, Z. V. Efeito da origem dos isolados do Cucumber mosaic vírus (CMV) e da presença de dois potyvirus na transmissão do CMV para abobrinha de moita por meio de duas espécies de afídeos. Dissertação (Mestrado em Agronomia). ESALQ - Universidade de São Paulo, 2003.

Ramos, N. F.; Lima, J. A. A.; Santos, A.A.; Gonçalves, M.F.B. (2003), Plantas de meloeiro com infecção mista de espécies de vírus em campos experimentais. Fitopatologia Brasileira, 27, p.211, 202. Suplemento

Silveira, L. M.; Queiroz, M. A.; Lima, J. A. A.; Nascimento, A. K. Q.; Neto, I. S. L. (2009), Levantamento sorológico de vírus em espécies de cucurbitáceas na região do submédio São Francisco, Brasil. Tropical plant pathology, 34, 123-126. 
Stipp, Liliane Cristina Liborio. Transformação genética de abobrinha-de-moita e melancia para resistência ao Papaya ringspot virus - type Watermelon e ao Zucchini yellow mosaic vírus.

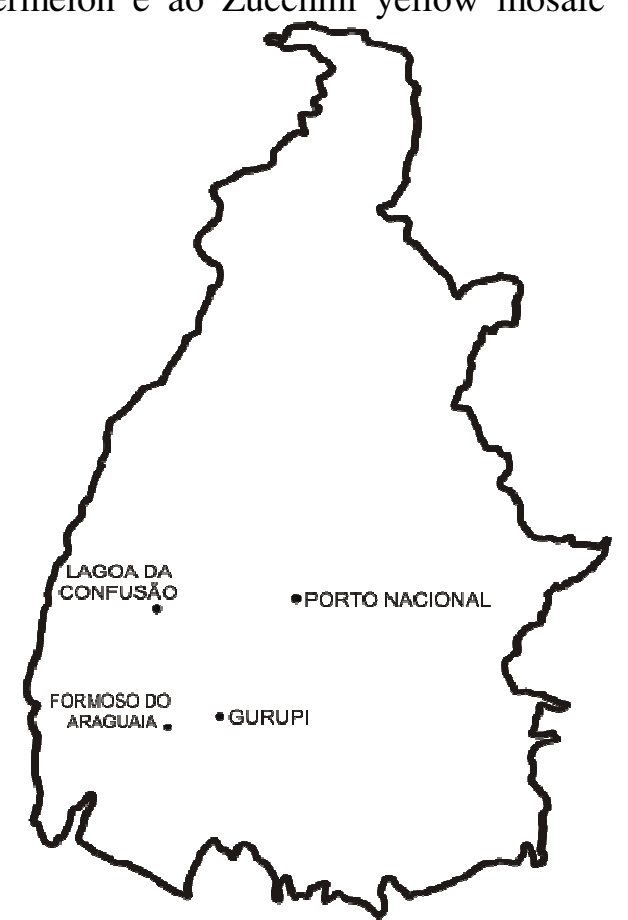

Figura 4 - Mapa do Estado do Tocantins indicando as cidades onde foram coletadas as amostras de vírus.
Tese (Doutorado em Fitopatologia) - Centro de Energia Nuclear na Agricultura, Universidade de São Paulo, Piracicaba, 2009. 